NOTAS

\title{
LA PASIÓN POR LA EXISTENCIA EN LA OBRA DE JOSEFINA VICENS Ma. Halina Vela*
}

\begin{abstract}
"Lánzate a tu vida desnudo, inexperto, inocente. Y sal de ella maltrecho o victorioso. Eso, al fin y al cabo, es igual. Lo importante es la pasión que hayas puesto en vivirla". ${ }^{1}$
\end{abstract}

L

a obra de Josefina Vicens está considerada entre las más importantes dentro de la narrativa mexicana contemporánea. El libro vacio publicado en el año de 1958, y por el que Josefina Vicens recibiera el Premio Xavier Villaurrutia vino a romper, por el tipo de cuestionamientos que planteaba y por la forma como lo hacía, con toda una tradición de la narrativa mexicana.

El libro vacio, a diferencia de Los años falsos, segundo libro de Josefina Vicens publicado en el año de 1982, se

" Centro de Lenguas, ITAM.

${ }^{1}$ Vicens, Josefina. El libro vacío. $1^{\mathrm{a}} \mathrm{ed}$., 1978, p. 136. inserta en un contexto más universal, ya que su acento está puesto en el Hombre. En la medida que avanzamos en la lectura vemos que esta obra fue escrita desde lo más íntimo del hombre, para llegar a lo más íntimo del mismo.

Sollocé inconsolable por lo que se moría, antes de vivirlo. Sin saberlo, creyendo que lloraba por mí, en realidad lloraba por los dos más agrios dolores del hombre: el amor y el adiós. ${ }^{2}$

${ }^{2}$ Ibid., p. 66. 
NOTAS

José Garcî̉, personaje y narrador de El libro vacio es un hombre común, tan común como su nombre y apellido lo indican, más sin embargo, el tipo de reflexiones que se plantea y nos plantea, no son en modo alguno comunes.

El libro desde su inicio nos introduce a la interioridad del personaje. Este es un ser escindido por lo que desea hacer, escribir un libro, y por lo que realmente hace, la novela termina sin que su personaje haya podido, aparentemente, escribir el libro que soñaba:

Esa luz, iqué fastidio! En fin, voy a acostarme y a seguir pensando. Tengo que encontrar esa primera frase. Tengo que encontrarla. ${ }^{3}$

José García vive entre dos quehaceres que caminan paralelamente: el quehacer literario y el quehacer existencial. Ambos proyectados desde el quehacer mismo. Es decir, la problemática de la creación literaria está planteada desde la creación misma. Por otro lado, el quehacer existencial queda encarnado en todos y cada uno de los actos realizados por el personaje, por ese hombre que se nos presenta como un inacabado proyecto a la manera existencial sartreana, ya que no se trata sólo de escribir un libro -hecho que lleva a la autora a reflexionar acerca del sentido de la escritura, del por qué y para qué escribir- sino que se trata también, de la elección de uno mismo:

${ }^{3}$ Ibid., p 230.
Así como tracé un plan cuando pretendía escribir una novela, del mismo modo, desde muy joven, hice un apasionante proyecto de $\mathrm{mi}$ vida. ${ }^{4}$

A lo largo del desarrollo de la novela observamos la recurrencia a temas sartreanos, tales como: la presencia de la "nada", la imposibilidad de comunicación entre los hombres, la soledad, la condena a vivir dentro de un cuerpo que no elegimos, así como a morir sin remedio:

no sé por qué me siento ajeno a mí; como si accidentalmente hubiera yo caído dentro de mi cuerpo y de pronto me diera cuenta del sitio en que habito. 5

Ahora, con respecto al hecho de que El libro vacio se inserte en un contexto más universal que el de Los años falsos, está relacionado con el tipo de influencias que en él encontramos. Es evidente que esta obra forma parte de la novela moderna, ya que en ella se manifiesta toda la herencia que nos dejaron autores como Marcel Proust, James Joyce, Musil, Kafka, etc., quienes realizaron descripciones de sus personajes a partir de su interioridad. Y Josefina Vicens, tanto en El libro vacío como en Los años falsos viene a realizar una exploración minuciosa de

\footnotetext{
${ }^{4}$ Ibid., $\mathrm{p} 95$.

${ }^{5}$ Ibid., p 47.
} 
los yos de sus personajes. Así tenemos frente al personaje de José García, quien se debate entre su deseo de escribir y la imposibilidad de hacerlo, a un Luis Alfonso, protagonista y narrador de Los años falsos, que se debate entre el vivir o el no vivir, y entre ser él o ser un otro que no es él.

José García sufre por la elección. Pero no sólo por la sostenida cotidianamente entre sus dos yos, sino por la elección que implica tomar sólo una parte del todo y no al todo mismo:

Lo quería todo y no me resignaba a elegir, porque la elección significaba un corte al total anhelado. ${ }^{6}$

Luis Alfonso sufre por no decidirse a matarse, o a matar. La elección de su vida, la muerte de su padre, terminaría siendo su propia muerte, ya que para su madre y hermanas él sólo existe en tanto asuma la personalidad del padre muerto.

En realidad la única muerte a la que nos enfrentamos es a la del propio Luis Alfonso. Es a él a quien le han robado la vida misma, el derecho a ser:

Yo podría hablarte de lo que es estar allá abajo, contigo, en tu aparente muerte, y de lo que es estar aquí arriba, contigo, en mi aparente vida. ${ }^{7}$

${ }^{6}$ Ibid., p 120.

${ }^{7}$ Vicens. Los años falsos, p. 23-4.
Algunos autores, al analizar el papel que desempeña "la mujer" en las obras de Josefina Vicens (la esposa de José García en El libro vacío, y la madre de Luis Alfonso en Los años falsos) han afirmado que éstas responden al prototipo de la mujer mexicana de aquellos años: la mujer abnegada, pasiva, dependiente del hombre, en tanto no le ha sido posible desarrollarse profesionalmente. Yo creo que esto no es así. En el caso de la esposa de José García, es en ella en quien está depositada la fuerza, la sabiduría. Las decisiones importantes son tomadas por esta mujer, quien en palabras de José García:

ha sido toda su vida, un bello lago sin el pudor de su fondo. Se asoma uno a él y lo ve todo...

En el caso de la madre y hermanas de Luis Alfonso, creo que más que reflejar una determinada realidad de la época, sus personajes van a girar en torno al problema de Luis Alfonso. Es decir, en El libro vacio Josefina Vicens trata de señalar todas, o casi todas las características inherentes a la condición humana. Aunado a esto, tendríamos también la problemática de la creación literaria desde la creación literaria, y también estaría presente un cuestionamiento acerca de lo que es la existencia para el hombre moderno, para este hombre moderno que ve ahogarse sus sueños en forma cotidia-

${ }^{8}$ Vicens. El libro vacio, p. 20. 
NOTAS

na. José García se nos presenta así como este hombre moderno que a través de la escritura tratará de salvarse del vacío existencial que lo agobia. Luego entonces, podríamos afirmar que el arte se nos presenta como la única posibilidad de salvación del hombre, justamente porque es su capacidad creativa la que lo distingue del resto de los animales.

Ahora bien, retomando a Luis Alfonso tenemos lo siguiente. Los años falsos llamará la atención del lector en torno a un problema que, a simple vista, podría definirse como de identidad. Sin embargo, la atención del lector quedará fijada en un problema más serio: el de la simbiosis de Luis Alfonso con su padre.

¿Por qué yo no te encontraba en mí? ¿Por qué aseguraba la gente, incluso mi madre, que éramos exactos? Yo sólo veía en el espejo una cara grotesca, sin vida, haciendo muecas absurdas. ¿Será porque lo preparo y me vigilo? -decía. Entonces me retiraba del espejo, pensaba en otra cosa, tomaba un libro y leía unas cuantas páginas, o me quitaba los zapatos y los cepillaba tenazmente. De pronto, cuando calculaba que ya había quedado rota la premeditación, corría al espejo para sorprenderme.

iPero sólo veía la cara ansiosa de un joven que te buscaba, papá, que te buscaba! ${ }^{9}$

${ }^{9}$ Vicens. Los años falsos, p. 26.
Luis Alfonso llega a asumir la personalidad del padre a tal grado, que llega un momento en que ya no le es posible diferenciar hasta dónde es él, y hasta dónde es su padre.

¿Qué diferencia existe entre tú y yo? ¿No lograste que no la hubie$\mathrm{ra}^{10}$

El medio familiar y el social han orillado a Luis Alfonso a llevar la situación al extremo, ya que termina siendo amigo de los amigos de su padre, y amante de la amante de su padre.

Ahora bien, el papel que desempeña "la mujer" en Los años falsos creo que fue prepositivamente disminuído, ya que se trataba de señalar, básicamente, el problema de simbiosis que Luis Alfonso vivía respecto de su padre. O dicho de otro modo, la fuerza ejercida sobre Luis Alfonso, tanto la del medio familiar como la del medio social, está dada en función del propio Luis Alfonso.

No olvidemos que es su propia madre, quien constantemente le está demandando jugar un rol que no le pertenece. Luis Alfonso no ha heredado sólo la ropa y objetos personales de su padre, ha heredado también a su madre-esposa, y a sus hermanas-hijas. Todos los que le rodean no hacen sino hablarle acerca del enorme parecido con su padre. Así, Luis Alfonso termina adoptando no sólo los gustos y ac${ }^{10}$ Ibid., p. 43. 
NOTAS

titudes de aquél, sino que se adueña de todo lo que le pertenecía.

...vine a verte... Recuerdo que dije en susurro una frase tonta, ... Se murió toda mi familia. Y de inmediato sentí que si todos me habían dejado. ...Pero no era eso. No era eso. Tú no estabas ahí. Estaba yo. Y estaban también mi madre y mis hermanas. Afuera habían quedado, contigo, conmigo, tu mujer y tus hijas. Esas desconocidas, esas tramposas, esas dóciles que esperaban mis órdenes. ${ }^{11}$

-Ahora tú eres el señor de la casame dijo mi mamá el día que empecé a trabajar.

Pero no me dijo que desde ese mismo día dejaba de ser mi madre. Eso no me lo dijo. ${ }^{12}$

La sumisión de la madre de Luis Alfonso, así como de las hermanas, tiene que ver con un patrón de conducta que ya en muchos sectores ha ido desapareciendo. Me refiero a todo ese bagaje educacional que heredamos, en gran parte, desde el tiempo de la Conquista.

"El hombre" en Los años falsos, me refiero al tipo que se señala como "el padre", es el clásico macho que se emborracha para demostrar que es muy hombre. Es aquel que nunca se compromete afectivamente, porque

\footnotetext{
${ }^{11}$ Ibid., p. 73.

${ }^{12}$ Ibid., p. 46.
}

en realidad nunca ha madurado. Esto me hace pensar en la tesis del libro de Santiago Ramírez: El mexicano. Psicología de sus motivaciones, donde se plantea que la estructura familiar mexicana es: exceso de madre, ausencia de padre y abundancia de hermanos. Aplicando esta tesis a la obra de Josefina Vicens podríamos decir lo siguiente: En El libro, vacío si se analiza la relación de José García respecto a su familia, veamos que no es del todo una relación comprometida. José García se encierra a solas para escribir. Por un lado, vive imaginando que algún día se irá; ese apego que en realidad siente es lo que más le molesta; entre más arraigado se siente, más se incrementa su deseo por liberarse. Por otro la madre y las hermanas de Luis Alfonso en realidad no existen. Aquí si podríamos hablar de casi una total ausencia por parte del padre, para quien "la mujer" no tiene ningún valor, salvo el de seryir para cuidar la casa y los hijos. La mujer no pregunta, está totalmente marginada de la vida del hombre. Su papel es el de "la espera". Esperar a que éste llegue, siempre a la hora que lo desee y cómo lo desee. Ella está ahí sólo para atenderlo.

Esta simbiosis de Luis Alfonso tiene en sus raíces un amor-odio que han ido consumiendo su vida. Amor, porque recuerda las pocas veces que su padre le brindó atención, y se aferra a ellas, como si se tratara de un naúfrago aferrándose a un salvavidas. Odio, porque en el fondo Luis Alfonso cono- 
NOTAS

ce a su padre y ha experimentado, en carne propia, su incapacidad afectiva.

Cuando al fin te alejabas, yo contemplaba mis despojos y tus señales, tus grandes huellas, imperativas, renovadas. ${ }^{13}$

En la siguiente cita podemos observar toda la rabia de Luis Alfonso al hablar, con su padre, de su madre:

Me habló... de lo que habías sido para ella, de lo feliz que fue su matrimonio, de la falta que le hacias y de que su vida había terminado el día de tu muerte.

Poco a poco iba creciendo en mí una especie de ira celosa pero yo la dejaba crecer porque sentía que me estaba conduciendo a la verdad... En voz baja (para que no me oyeras), arrastrando las palabras, dándoles el untuoso tono de la perversidad, le dije:

Pero acuérdate que nunca te sacaba a pasear, ni te traía ningún regalo... acuérdate cómo te gritaba cuando estaba enojado... acuérdate que todo se lo gastaba con los amigos... acuérdate... ${ }^{14}$

Los medios laborales en los que se desenvuelven los personajes son los siguientes: José García se desenvuelve

${ }^{13}$ Ibid., p. 76.

${ }^{14}$ Ibid., p. 81-2. en la burocracia, que se le presenta como una institución laberintica que amenaza con devorarlo.

Este medio fue muy conocido por la autora y lo dijo en diversas entrevistas, ya que ella misma trabajó como burócrata. Además, tuvo la oportunidad de conocer el ambiente de la política al participar en diversas campañas políticas, así como entrar en contacto con los campesinos. Todo esto quedó plasmado en el ambiente laboral del padre de Luis Alfonso.

Los entornos familiares y sociales presentados, tanto en El libro vacio como en Los años falsos, son en realidad un simple marco, en cuyo centro tendremos siempre la presencia del Hombre. De este hombre moderno representado por José García, quien lucha tenazmente por conciliar su ser racional con su ser irracional, o si se quiere, su ser conciente con su ser inconsciente, o hablando en términos sartreanos, su ser "en-sî" (el ser), con su ser "para-sî" (la conciencia existente). En síntesis tenemos a un hombre: José García, quien tiene una sed insaciable del "todo", frente a un joven; Luis Alfonso, quien tiene una sed insaciable de la "nada". Así, el "todo" y la "nada", la vida y la muerte, vienen entremezclándose en ambos relatos, quizá como un reflejo de lo que su autora, Josefina Vicens, sentía:

No sólo no tengo miedo a la muerte, sino un deseo feroz de ella. Quizá se deba precisamente a mi 
NOTAS

vocación de vivir, a esa vocación que me lanzó desde muy joven al mundo, a conocer personas, a convivir con campesinos, ir a campañas políticas, conocer un manicomio, aficionarme a los toros, investigar el cine, buscar la escritura... ${ }^{15}$ (González. Dueñas, A. Toledo. Josefina Vicens. La inminencia de la primera palabra. UNAM).

Creo que una de las tesis presente en ambas novelas, estará relacionada con la forma como la autora nos presenta a sus personajes.

En el caso de José García, su presencia nos remitiría a lo que en términos de Milán Kundera equivale a "el rescate del ser", de este ser -el hombre del siglo veinte- que ha caído en el olvido. La autora no lo plantea así, pero lo que sí cuestiona es el por qué de la existencia y el para qué de la creación. El mismo título del libro creo que estaría llevándonos a través de su sin sentido a la búsqueda del sentido.

Así vemos como José García vive obsesionado, pero no sólo por escribir un libro, sino también por lograr establecer la comunicación, esa comunicació ' que casi se antoja como imposible hoy en día con alguno de sus semejantes. No entiende por qué razón aquellos que le rodean no comparten sw. sueños, sus obsesiones, sus preguntas.
No entiende, todavía, que lo que lo separa de los otros es justamente el hecho que él, a diferencia de ellos, se sabe temporalidad, se sabe finitud, se sabe placer y se sabe dolor. Y es este saber lo que lo convierte en artista, porque como el mismo nos lo confiesa: un artista es aquél que posee todos los dolores que los demás hombres poseen, y uno más: el de la creación.

En el caso de Luis Alfonso, él se encuentra menos ligado, afectivamente a lo que le rodea. Aún no se siente arraigado a una mujer, a unos hijos. Su edad aún no le ha enseñado las ataduras de la convivencia. Luis $\mathrm{Al}$ fonso no gira alrededor del mundo, tan solo gira alrededor de si mismo, en torno a ese amor-odio que siente por su padre. Ese amor-odio que es placer y dolor, que es también vida y muerte al mismo tiempo:

Pero ¿sabes papá? Te lo digo quedito, al oído, sin que me veas, sin que nadie nos oiga. Lo que yo quisiera es: no ser el marido y el hijo de mi mamá; no el padre y el hermano de mis hermanas, ni, por ser hijo tuyo, el amigo de tus amigos; ni el protegido y ayudante de un político; ni tu rival y tú cómplice; ni yo-tú, ni tú-yo; ni el amante a medias de Elena. Lo que yo quisiera, papá, es tener otra vez seis años y oírte dẹ:- "vámonos a dar una vuelta", o "verás cómo nos vamos a divertir" o "voy a llegar tarde, hijo,

${ }^{15}$ Glez. Et. Toledo, p. 48. 
NOTAS

pero si piensas en mí todo el tiempo tal vez regrese más temprano". ..."Eso papá, que ya no puede ser, o que en este justo momento, hoy que es tu cuarto aniversario, aquí, de pie ante la tumba, suceda lo que he deseado intensamente, todos, todos los días: morirme, tener mi caja, mi lápida, mi reja de alambrón, mi cruz, mi bugambilia, mi lagartija, y mis propios gusanos, mis propios gusanos, míos, míos. Tengo derecho, ya que no lo tuve a la vida, a tener una muerte entera. ¿Me comprendes, papá? Enteramente mía. ${ }^{16}$

Así podemos observar que, tanto José García, como Luis Alfonso, nos llevan a establecer la tesis principal alrededor de la cual giran ambos relatos: que el hombre no puede ser otro que él mismo. Dicho en las palabras de José García:

...soy lo que he sido y seré siempre: un hombre que necesita escribir y vivir encerrado en su cárcel natural e intransferible. ${ }^{17}$

Esta cárcel natural e intransferible de la que habla José García, bien sabemos que es la misma para todos, pero, es también "otra".

${ }^{16}$ Vicens. Los años falsos, p. 101.

${ }^{17}$ Vicens. El libro vacio, p. 213. 